\title{
Engaging End-Users to Maximise Uptake and Effectiveness of a New Species Recovery Assessment: The IUCN Green Status of Species
}

\author{
Molly K. Grace ${ }^{a, \#}$, Hannah L. Timmins ${ }^{b}$, Elizabeth L. Bennettc ${ }^{c}$ Barney Longd, E.J. Milner-Gullande, \\ Nigel Dudley

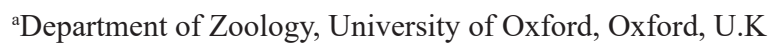

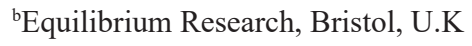

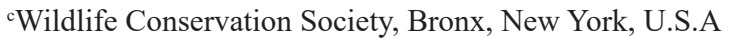 \\ ${ }^{\mathrm{d}} \mathrm{Re}$ Wild, Austin, Texas, U.S.A \\ ${ }^{\mathrm{e}}$ Merton College, University of Oxford, Oxford, U.K
}

\#Corresponding author. E-mail: molly.grace@zoo.ox.ac.uk

\begin{abstract}
When developing a novel conservation assessment, tradeoffs between generality and precision, and between realism and simplicity, will inevitably need to be made. Engaging potential end-users during development can help developers navigate these tradeoffs to maximise uptake. End-user engagement can also produce feedback about external perceptions, allowing changes to be made prior to the final design. Here, we report on end-user consultations about the species recovery assessment method introduced by the International Union for Conservation of Nature (IUCN), which is a new component of the IUCN Red List of Threatened Species. This species recovery assessment was originally called the 'Green List of Species.' We conducted two types of end-user consultation over a two-year period-1) key informant interviews, and 2) technical consultations about the details of the assessment method, including identification of factors that increased the amount of time required to conduct an assessment. A main finding from the key informant interviews was that the name 'Green List of Species' was inappropriate for the assessment, given the potential for misunderstanding the scope of the assessment and potential confusion with the IUCN Green List of Protected and Conserved Areas. We therefore proposed the name 'Green Status of Species', a suggestion accepted by IUCN. A repeated concern in key informant interviews was the perception that the species recovery assessments were complex, indicating a potential tradeoff between scientific rigour and simplicity. To address this concern, we used feedback from the technical consultations to identify assessment steps which were most in need of refinement, and implemented solutions and made recommendations to streamline those steps (e.g., we found that the number of spatial units used in an assessment was positively correlated with assessment time, and increased greatly when more than 15 spatial units were used). This process of end-user engagement makes it much more likely that the Green Status of Species will be used in conservation communication, monitoring, and decision-making - helping achieve the ultimate goal of biodiversity recovery.
\end{abstract}

Keywords: consultation, Green List, key informant, Red List, species conservation, thematic analysis

Link to supplementary material: https://bit.ly/2UuRpvn

\begin{tabular}{|l|l|}
\hline \multicolumn{2}{|c|}{ Access this article online } \\
\hline Quick Response Code: & Website: \\
\hline & www.conservationandsociety.org.in \\
\cline { 2 - 3 } & \\
\hline
\end{tabular}

\section{INTRODUCTION}

Participatory approaches, which widen a decision-making process to include stakeholders who will potentially be affected by the outcome, are becoming increasingly common in biodiversity conservation science and practice (Jones-Walters and Cil 2011; Sterling et al. 2017). Stakeholder engagement during the design stages of a new tool or intervention helps to refine methods, minimises conflict and

Copyright: Grace et al. (c) 2021. This is an open access article distributed under the terms of the Creative Commons Attribution License, which permits unrestricted use and distribution of the article, provided the original work is cited. Published by Wolters Kluwer - Medknow, Mumbai | Managed and supported by the Ashoka Trust for Research in Ecology and the Environment (ATREE), Bangalore. For reprints contact: WKHLRPMedknow_reprints@wolterskluwer.com 
disengagement, and can be key to maximising successful implementation and uptake (Fazey et al. 2013). When developing novel conservation methods, one important group of stakeholders is end-users, who will need to use the method to generate data and/or use the data generated by the method to inform decisions (e.g., Maxwell et al. 2018).

Participatory approaches that engage end-users can be extremely useful in understanding and navigating the tradeoffs that inevitably arise when designing conservation assessments for use at the global level. Conservation assessments are based on models of how systems and processes function (e.g., the Red List classification system for species extinction risk is based on a model of extinction processes; Mace and Lande 1991; Mace et al. 2008), and models must strike a balance between generality (i.e., applicability of the model across cases), precision (i.e., the confidence range of model outputs), and realism (i.e., inclusion of as many variables/factors as are thought to be relevant) (Levins 1966). Because conservation assessments need to be communicated and understood easily by non-specialists (e.g., decision-makers and the media), another consideration in assessment building is simplicity/clarity (Keith et al. 2015), which might require reducing the number of variables. Designing a new global conservation assessment requires a delicate balance of these four qualities, and because increases in one quality generally come at the expense of at least one of the others, it is useful to engage potential end-users to learn which qualities they value.

The International Union for Conservation of Nature (IUCN), a key player in the development of novel conservation assessments, has long embraced participatory approaches (from Christoffersen 1997 to Maxwell et al. 2018; Hockings et al. 2019). Not only does IUCN's global membership of state agencies, NGOs, and indigenous groups (IUCN 2020) vote on directions for its scientific and technical commissions, but it is standard practice to engage the membership, especially end-users, during the development of a new conservation tool. This is an especially important step when IUCN is developing tools that are intended to be a global data standard. The IUCN Red List of Threatened Species, for example, has undergone two major revision and modification processes since its inception, with input from stakeholders and end-users (Mace and Lande 1991; Mace et al. 1992; Mace 2000; Mace et al. 2008). These revisions responded to calls from certain end-users to increase the generality and realism of the Red List of Threatened Species assessment process, while others desired increased precision and others still flagged the need for simplicity to aid in assessment communication (Mace et al. 2008). These trade-offs have also played out in the development of the IUCN Red List of Ecosystems (Rodríguez et al. 2012; Keith et al. 2015).

In 2012, IUCN members passed a resolution mandating the development of a method to assess successful conservation and recovery of species (IUCN 2012a). After six years of technical and scientific discussion, Akçakaya et al. (2018) proposed a draft framework for an IUCN Green List of Species: a novel approach for assessing species' progress toward recovery and the estimated impact of conservation actions, past and future, on species recovery (Figure 1). The publication of the draft framework was the first step in a two-year process of engaging end-users to guide the development of this species recovery framework to its final form; one early and oft-repeated piece of feedback was that the name 'Green List of Species' was potentially unsuitable. Here, we present the methods used to solicit end-user input on the underlying model and framing (including the name) of this new IUCN species recovery assessment, report on changes made as a result, and identify areas of tradeoff which will require future attention in order to maximise end-user uptake.

\section{MATERIALS AND METHODS}

The Akcakaya et al. (2018) framework was designed to assess recovery of a species at the global level (although there are plans to develop methods for national assessments; IUCN 2021). We identified two classes of end-user-1) people who would need to generate IUCN species recovery assessments at the global level (data generators), and 2) people who would generally not be involved in producing assessments, but might use the assessments to inform some aspect of their organisation's operations (data users). Because these classes of end-users were expected to have different needs and perspectives, we actively targeted both using two methods - 1) key informant interviews and 2) technical consultations.

\section{Key informant interviews}

We sought to obtain initial views on a wide number of aspects of the draft IUCN species recovery assessment by conducting short interviews with specialists in organisations which represent different types of potential end-users. These interviews were designed and carried out by Nigel Dudley (N.D.) and Hannah Timmins (H.T.). We targeted organisations from the following broad groups hypothesised to have an interest in species assessments a the global level: IUCN secretariat and commissions, conservation funders, intergovernmental conventions and UN bodies, international conservation NGOs, national/ regional conservation agencies (who might undertake "global" assessments of country endemics), organisations focusing on sustainable use and/or with industry associations, zoos and botanic gardens, and conservation researchers. These groups comprise both data generators and data users. Before beginning the interview, participants were told that they were not required to participate and that they could withdraw at any time.

Prior to the interview, participants were provided with the paper by Akçakaya et al. (2018), a summary explanation of the assessment method in an email, and the list of interview questions (Table 1). The amount of time spent by participants interacting with these documents was unknown, but these interviews likely represent surface-level reactions to the concept (with the exception of some IUCN participants in species-related roles, who were more familiar with the draft 


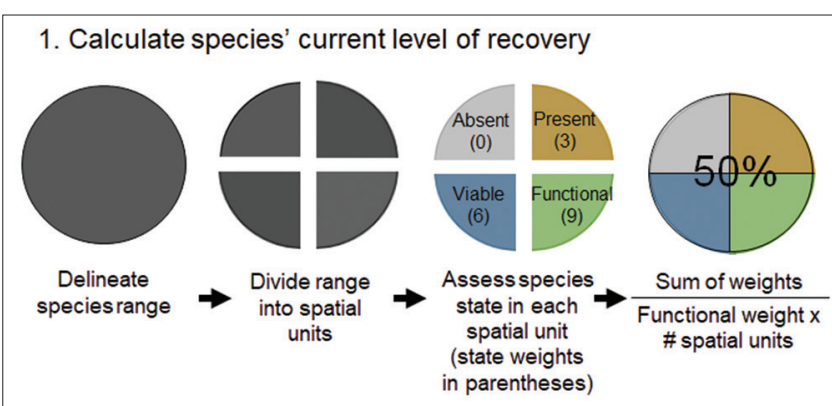

2. Estimate impact of conservation on recovery using scenarios

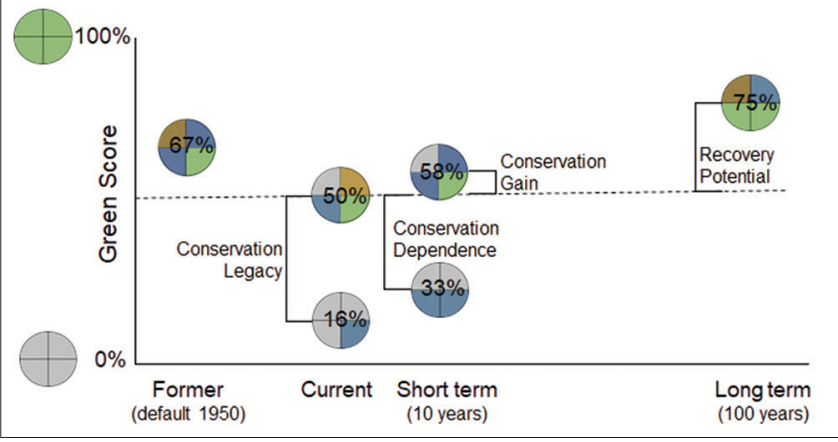

Figure 1

Summary of IUCN species recovery assessment process and outputs using a hypothetical species as an example. This is a simplified explanation that does not take into account all potential cases; for a full account, see IUCN 2021. The recovery assessment is based on the calculation of Green Scores, representing a species'current level of recovery $(0-100 \%)$ compared to a historical baseline. Calculation is based on based on the state (Absent, Present, Viable, or Functional) in subdivisions of the species' range (spatial units). Note that 'species range' refers to its indigenous (pre-impact) and expected additional range (IUCN 2021). Note also that while the range has been divided into four spatial units in this example, more or fewer spatial units, or only one spatial unit, can be used, as appropriate for the species. In phase 1, range and spatial units are delineated, and the species'current Green Score is calculated based on the observed, estimated, or inferred condition of the species in each spatial unit. In phase 2, the expected score under different hypothetical scenarios with and without conservation is estimated in order to evaluate conservation impact. The differences between the Green Scores in these scenarios and the current Green Score represent four conservation impact metrics (IUCN 2021): the benefit of past conservation (Conservation Legacy), the expected cost of halting conservation today (Conservation Dependence), the expected short-term gains if conservation continues (Conservation Gain), and the maximum

realistic recovery achievable for the species (Recovery Potential)

method). Interviews were conducted between October $3^{\text {rd }}, 2019$ and December $20^{\text {th }}, 2019$ by N.D. and H.T. either over Skype or by respondents answering a series of questions by email. At the time, the assessment was referred to as the Green List of Species (GLS), but the name was a subject of discussion in the consultation (Table 1). Following Skype interviews, results were written up in summary form for each participant, identifying the main points made, and shared to check that they accurately reflected the opinions of the participant. Further details are provided in Dudley and Timmins (2021).

The interviews were semi-structured, in that the same list of open-ended questions (Table 1) was presented to each participant, but participants could choose to skip questions. In particular, questions about technical
Table 1

Questions asked during key informant interviews

\begin{tabular}{|l|l|}
\hline Order & Question Text \\
\hline 1 & Is the Green List of Species needed? \\
\hline 2 & $\begin{array}{l}\text { What would be the value of a Green List of species for } \\
\text { your work? }\end{array}$ \\
\hline 3 & $\begin{array}{l}\text { If it was available, would you use it, and how would you } \\
\text { use it? }\end{array}$ \\
\hline 5 & $\begin{array}{l}\text { Specifically, would you use it purely at a species level or } \\
\text { would you require place-based or global indicators? }\end{array}$ \\
\hline 6 & $\begin{array}{l}\text { What type of product would be most useful (e.g. global } \\
\text { online database, national reports, annual report, etc)? }\end{array}$ \\
\hline 7 & $\begin{array}{l}\text { How well would a Green List of Species match with (or } \\
\text { clash with) existing tools and procedures? }\end{array}$ \\
\hline 8 & $\begin{array}{l}\text { Are there lessons from your experiences using other tools } \\
\text { designing the Green List? }\end{array}$ \\
\hline 9 & $\begin{array}{l}\text { For each of the four Green List axes (Legacy, Dependence, } \\
\text { Gain and Recovery), how many categories should there be } \\
\text { per axis? }\end{array}$ \\
\hline $\begin{array}{l}\text { For each axis can there be different categories (e.g. } \\
\text { Legacy=low, medium, high but Recovery Potential=near, } \\
\text { middle, far) or do people want the same categories for } \\
\text { each of the four axes (e.g. Legacy=low, Dependence=low, } \\
\text { Gain=low, Recovery Potential=low). }\end{array}$ \\
\hline 13 & $\begin{array}{l}\text { Should the Green List of Species be a standalone product, } \\
\text { nested within the Red List, or wholly consumed by the } \\
\text { Red List? }\end{array}$ \\
\hline 12 & $\begin{array}{l}\text { Is "Green List of Species" the right name, and if not, what } \\
\text { would be better? }\end{array}$ \\
\hline $\begin{array}{l}\text { Do you have any concerns or fears about developing the } \\
\text { Green List of Species? }\end{array}$ \\
$\begin{array}{l}\text { Are there any implications in what you have said for those } \\
\text { developing the Green List of Species? }\end{array}$ \\
\hline Any other comments? \\
\hline 14
\end{tabular}

issues in the assessment method were frequently omitted (e.g., Questions 8 and 9, Table 1). Therefore, when summarising interview results by end-user group we present data using raw numbers rather than percentages and, if necessary, indicate cases where no response was given. Participants were also given the opportunity to bring up any other thoughts that had not been suggested by the interview questions; Skype interviews often became quite free ranging, with participants diverging from strictly answering the questionnaire to cover a broader range of related topics.

Each interview produced a written document: either a participant-approved summary of the conversation (see above) or direct writing by the respondent in the case of email responses. These documents were analysed using thematic analysis (Braun and Clarke 2006). In thematic analysis, codes are applied to describe the common features of excerpts of data, which allows patterns in the data to be discerned. Codes can be grouped under themes; for example, 'user-friendly' might be a code under the theme 'desired properties.'

Interviews were coded in NVivo by Molly Grace (M.G.). The questions asked in the interview (Table 1) suggested many a priori themes and codes (e.g., theme $=$ 'name', codes = 'supportive', 'against,' 'neutral'). Some questions suggested themes (e.g., 'concerns') but not codes a priori. Therefore, 
interview transcripts and summaries were first read and re-read by M.G. while taking notes on whether or not the a priori themes and codes applied to the data, and noting other themes and codes that were identified in the data. M.G. also sent two selected excerpts to E.M., N.D., and H.T. for independent thematisation to check for potentially missed themes and codes. M.G. compared thematisations and altered accordingly. Once the list of themes and codes was finalised (Appendix 1), each interview was re-read to check for themes and codes. A final spot-checking phase to identify any excerpts where codes should have been applied in the previous steps, but had not been, was carried out using queries, searching all interviews for key words related to the codes; these excerpts were re-read and the code applied if relevant.

\section{Technical Consultations}

Because participants in key informant interviews may not have been familiar with the technical details of the recovery assessment method, we used another consultation method to receive feedback on the technical aspects of the method itself (and by extension, the underlying model of species recovery). In March 2020, representatives of IUCN Member Organisations (data users; https://www.iucn.org/about/members/ iucn-members) and all members of the six IUCN Commissions (data generators and users; https://www.iucn.org/about/ union/commissions) were invited to give comments on draft versions of two documents: the Standard for the IUCN species recovery assessment method (noting that the name was not yet fixed) (IUCN 2021), and the Background and Guidelines (IUCN Species Conservation Success Task Force 2020). For this consultation, participants were provided with the two draft documents and asked to submit general and line-by-line comments using an online platform over a period of two months.

Each comment was classified by type: Clarification Needed, Concern, Disagreement, Editorial (a comment regarding grammar or syntax which would not change the meaning), Supportive, Suggestion (recommendation of a new assessment element or removal of element), Misunderstanding (participant interpreted the text in a way that it was not meant), or Out of Scope. Comments could be classified as more than one type (e.g., Clarification Needed/Suggestion). To identify which parts of the assessment process were most in need of future attention by developers, we counted the number of comments which implied further work might be required (all types except Supportive, Editorial, Out of Scope) referring to each of the following steps: Determining Range, Delineating Spatial Units, Assessing State in Spatial Units, and Estimating Green Score under Scenarios (Figure 1).

We also consulted people who tested the recovery assessment method. Between 2017 and 2020, assessments of 181 species were completed following Akçakaya et al (2018), as proof of concept (Grace et al. 2021a). We asked assessors to report the amount of time they spent on each assessment, as well as whether they had experience conducting Red List of
Threatened Species assessments (elements of which are a key part of the species recovery assessment method). We further examined one particular aspect of the process that could greatly influence the time involved: the delineation of spatial units. Species state is determined for each spatial unit under each scenario (Figure 1), so in theory, the more spatial units there are, the longer the assessment will take. We evaluated the relationship between time spent on assessments and the number of spatial units using a linear model. We also wanted to evaluate whether having prior experience conducting Red List assessments (a categorical factor, Yes/No) affected this relationship, so experience was originally included in the model: $\operatorname{lm}$ (time \# spatial units*experience), but because of the presence of a significant interaction term, analyses were conducted separately for the two levels of experience (lm (time $\sim$ \# spatial units)). Assessment time (hours) and spatial units were both log-transformed to fit the assumptions of linear regression; normality and equal variance of residuals were confirmed by visual inspection.

\section{Integration of feedback}

The concerns and limiting factors raised in key informant interviews and technical consultations were reviewed by the IUCN Species Conservation Success Task Force and resulted in several changes to the Standard (IUCN 2021). These changes are stated in the Results.

\section{RESULTS}

\section{Key Informant interviews}

\section{Interview participants}

We contacted 59 individuals to participate in key informant interviews, but three declined and eight did not respond. In the end, we conducted 48 interviews with representatives of the following categories: IUCN secretariat and commissions $(n=13)$, conservation funders $(n=5)$, intergovernmental conventions and $\mathrm{UN}$ bodies $(\mathrm{n}=5)$, international conservation NGOs $(n=4)$, national/ regional conservation agencies $(n=6)$, organisations focusing on sustainable use and/or with industry associations $(n=6)$, zoos and botanic gardens $(n=7)$, and conservation researchers $(n=2)$. See Dudley and Timmins (2021) and Appendix 2 for a full list of interview participants and organisations.

\section{Interview codes}

Themes and codes are denoted in the text by single quotes (e.g., 'desired properties'). For a full list of codes and the criteria used in coding, see Appendix 1.

\section{Desirability and expected use}

We first explored whether or not the participants we interviewed 1) thought that species recovery assessments as defined in Akçakaya et al (2018) were desirable, 2) would use the outputs of these assessments, and 3) if so, what potential 
uses they identified. Interviews in the category 'IUCN' are not discussed for these factors, because the species recovery assessment was originally requested by IUCN's membership, implying that IUCN will use it regardless. At the time, the product was still called the Green List of Species (GLS), and participants referred to it as such.

The 35 non-IUCN interviews indicated that IUCN species recovery assessments, regardless of name, are desired. Most interviews were coded as expressing 'interest' in the assessment method and outputs; only six interviews were not (three in the category 'Conservation Funders', two in 'Sustainable Use/Industry', one in 'Conservation Researchers'). In addition, participants in 19/35 interviews specifically indicated that the assessment 'fulfils a need'. These included the need for a definition and vision of species recovery; the need for a way to communicate conservation success; the need for species recovery baselines; the need for finer-scale assessments of species status; the need to understand the risks of removing protections on species; and the need to show conservation impact in the short term.

Participants in 28/35 non-IUCN interviews discussed whether their organisation would use the recovery assessment outputs. Of these, no participants indicated that they would not use them under any circumstances; 16 interviews were coded as would use, and 12 interviews were coded as 'selective/conditional use' (Appendix 3). The code 'selective/conditional use' was most often applied to interviews in the categories 'Sustainable Use/Industry' and 'Conservation Funders'. In interviews coded 'selective/conditional use', participants indicated that the assessment outputs would not be particularly helpful for their organisation but that they might use the information in certain circumstances, or that something would need to be changed for them to use it. For example,

"For GLS to be valuable to [Sustainable Use/Industry organisation] we would need to see some metrics around habitat intactness and quality relative to the historical range. Our plan is to support good NGOs that are already doing this work and we see the value of a forest not just in terms of habitat but also ecosystem services, carbon etc. I don't think we'll have the luxury of picking and choosing so I don't want to narrow down our options. Having said that, if the project is in an area of critical habitat for species X on the GLS we would love to support that."

Finally, we coded seven expected or desired uses for the recovery assessments that were discussed by participants: 'communicate success,' 'decision-making, 'fundraising tool', 'incentivise conservation,' 'measure conservation impact,' 'monitoring,' and 'planning' (Appendix 3).

Even in this relatively small sample of 35 interviews, end-users across different sectors suggested a wide range of potential uses. While some of these uses were in line with the reasons behind IUCN's development of a species recovery assessment method ('communicate success,' 'incentivise conservation,' 'measure conservation impact'; IUCN 2012a), other commonly voiced expected or desired uses went beyond anticipated uses. This applies particularly to the desired use of the IUCN recovery assessments in conservation 'planning.' While the method was developed to be a scientific assessment which can inform planning processes, rather than be part of the planning process itself, participants in 12/35 interviews indicated that results should help guide planning; eight interviews additionally suggested that assessment output should include concrete 'management actions' (Appendix 4).

\section{Desired properties of a species recovery assessment}

Several questions asked during key informant interviews prompted participants to discuss what characteristics they wanted to see in a species recovery assessment (Table 1; Appendix 4). We specifically asked about some characteristics; for example, when asked whether the IUCN species recovery assessments should be integrated with the IUCN Red List of Threatened Species (Question 10), participants in 30/48 interviews indicated yes, 3/48 indicated no, and 15/48 did not answer the question. We also asked if an online database would be a useful format (Question 5), and every participant who discussed the possibility of an online database (17/48) did so in a positive way, though one participant did balance the recommendation with the need to ensure access to the information by people with varying access to the internet, as well as varying technical abilities.

The desire that the assessments be accessible to all was reflected in several characteristics which were not prompted by the questions, but which were brought up repeatedly in interviews nonetheless (Appendix 4). Key among these were calls that the method and outputs should be simple (20/48 interviews), easy-to-use (13/48), and that the underlying process be transparent $(9 / 48)$.

The interviews also asked whether end-users were satisfied with the species-level focus of the recovery assessment, or if they would require place-based (e.g., ecosystem-level or national-level) information, or would prefer an index based on multiple species assessments to serve as a global indicator of recovery trends (Question 4). While the majority of interviews (28/48) did not touch on this subject, most of those that did indicated that species-level information would be useful to them (13/20). Calls for a multi-species indicator approach $(5 / 20)$ were made in interviews with participants in the categories 'Intergovernmental', 'IUCN', 'NGOs,' 'Conservation Funders,' and 'Zoos and Gardens.' Finally, only two interviews indicated that an ecosystem-level approach to generation of recovery data would be more useful to them than a species-based approach (FAO and IUCN Global Business and Biodiversity Programme). However, 20 interviews indicated that development of guidelines for conducting assessments at the national level would be welcome.

\section{Challenges}

Questions 7, 12, and 13 (Table 1) prompted discussions of potential challenges around development and use of the species recovery assessment methods (Table 1). Twenty-nine out of forty-eight interviews voiced concerns that should be considered 
as the method continues to evolve (Appendix 5). The vast majority of concerns had to do with generation of assessments; however, it is interesting to note that these concerns were expressed not only by participants representing data-generating organisations, but also by participants representing strictly user organisations (e.g., Conservation Funders, Intergovernmental, Sustainable Use/Industry Associations). The most common concern (Appendix 5) across interviews was that 'resource limitations' regarding funds, people, and time could mean that species recovery assessments would be de-prioritised, or that they could come at the expense of other conservation assessments/activities, like Red List of Threatened Species assessments. While the majority of participants who commented on the relationship between the recovery assessments and Red List assessments indicated that they are 'complementary to the Red List' $(n=20)$ rather than potentially 'in competition' $(n=7)$, this concern must be taken into account. The second most common concern (Appendix 5), tied to the concern about limited resources, involved the 'complexity' of the assessments. For example,

"Excessively complicated methods will be a problem; a perfect system that is little used because it is too onerous."

Concerns that spanned both the generation of species recovery assessments and the use of the resulting data included concerns that focusing on recovery could be a 'distraction' from stemming the decline of threatened species; that the 'subjective' elements of assessments could dissuade people from engaging seriously with the process; that subjectivity introduces 'potential for exploitation' in that assessors might try to tweak assessment inputs to get a desired result; and that the assessments might therefore be considered 'controversial' (Appendix 5).

\section{Communication pitfalls and 'Green List of Species' name}

Participants brought up a number of points coded as 'communication pitfalls,' including the worry that people might mistakenly conflate the Red List category of Least Concern with species that have recovery assessments, or mistakenly believe that species with a recovery assessment are "off the Red List"; there was also concern that people might interpret that a species with low Recovery Potential is not worth saving. These pitfalls are important and should be avoided with proactive messaging. However, the vast majority of excerpts coded as 'communication pitfalls' had to do with the name 'Green List of Species' itself.

Question 11 (Table 1) specifically asked participants how they felt about the name. While there were strong opinions both in favour of and against the name 'Green List of Species' (Figure 2), the frequency of these opinions was heavily skewed toward the 'against' position. Participants in 34 of 48 interviews expressed an opinion on the name, with 3 opinions coded as strictly 'supportive', 16 strictly 'against', and 9 strictly 'neutral'. Participants in two interviews offered both 'supportive' and 'against' views, and participants in four interviews offered both 'neutral' and 'against' views. See Figure 2 for examples of coded excerpts.
Participants raised a number of issues with the name 'Green List of Species' (Figure 2). At the most fundamental level, some participants suggested that because the assessment produces five outcome metrics (Figure 1), rather than a simple designation, that the name 'List' was not appropriate. Some flagged the potential for miscommunication: that people would assume that species "on the Green List" were recovered and no longer in need of conservation action, which is not always the case. Others were concerned specifically about end-user confusion which could result from introducing another 'List' metric in addition to the Red List of Threatened Species, the Red List of Ecosystems, and especially the Green List of Protected and Conserved Areas (GLPCA; IUCN and WCPA 2017). Thirteen participants specifically mentioned the GLPCA in statements coded as 'against' the name, and many cited the conceptual differences between the proposed Green List of Species and the GLPCA as too great for the two tools to share a name. Finally, some participants cited their desire that the recovery assessment be seen as an extension of the Red List of Threatened Species as a reason to reconsider the name. Importantly, of the end-users representing IUCN that commented on the name (11/13), there was only one interview that expressed support for the name (and it was accompanied by a negative counterpoint), and the majority (7/11) expressed unequivocally negative views.

\section{Technical Consultations}

\section{IUCN consultation}

In the technical consultation with IUCN members, 2730 people viewed the consultation instructions, 540 began the consultation and 54 submitted comments ( $10 \%$ completion rate). Comments were received from IUCN members residing in 28 countries across all continents except Antarctica. Nearly half of these 54 participants (44\%) were affiliated with the Species Survival Commission (data generators). $46 \%$ were affiliated with the other IUCN Commissions and Secretariat (data-users); $22 \%$ with IUCN member organisations (data-users); $4 \%$ indicated that they were not affiliated with IUCN (note that participants could mark multiple affiliations). Thirty-six participants contributed a total of 190 line-by-line comments on the Standard and Background and Guidelines documents, which were used to identify areas where the method could be refined.

These line-by-line comments were classified as follows: Suggestion (70), Clarification Needed (61), Editorial(44), Supportive (10), Concern (8), Disagreement (6), Misunderstanding (6), Out of scope (2). Seventy of these comments both referred to steps of the assessment process and indicated the need for further attention/development (all types except Supportive, Editorial, Out of Scope). More of these comments referred to the steps Assessing State in Spatial Units and Estimating Green Score under Scenarios (24 comments each) than to the steps Determining Range and Delineating Spatial Units (11 comments each). In this paper, 
156 / Grace, et al.

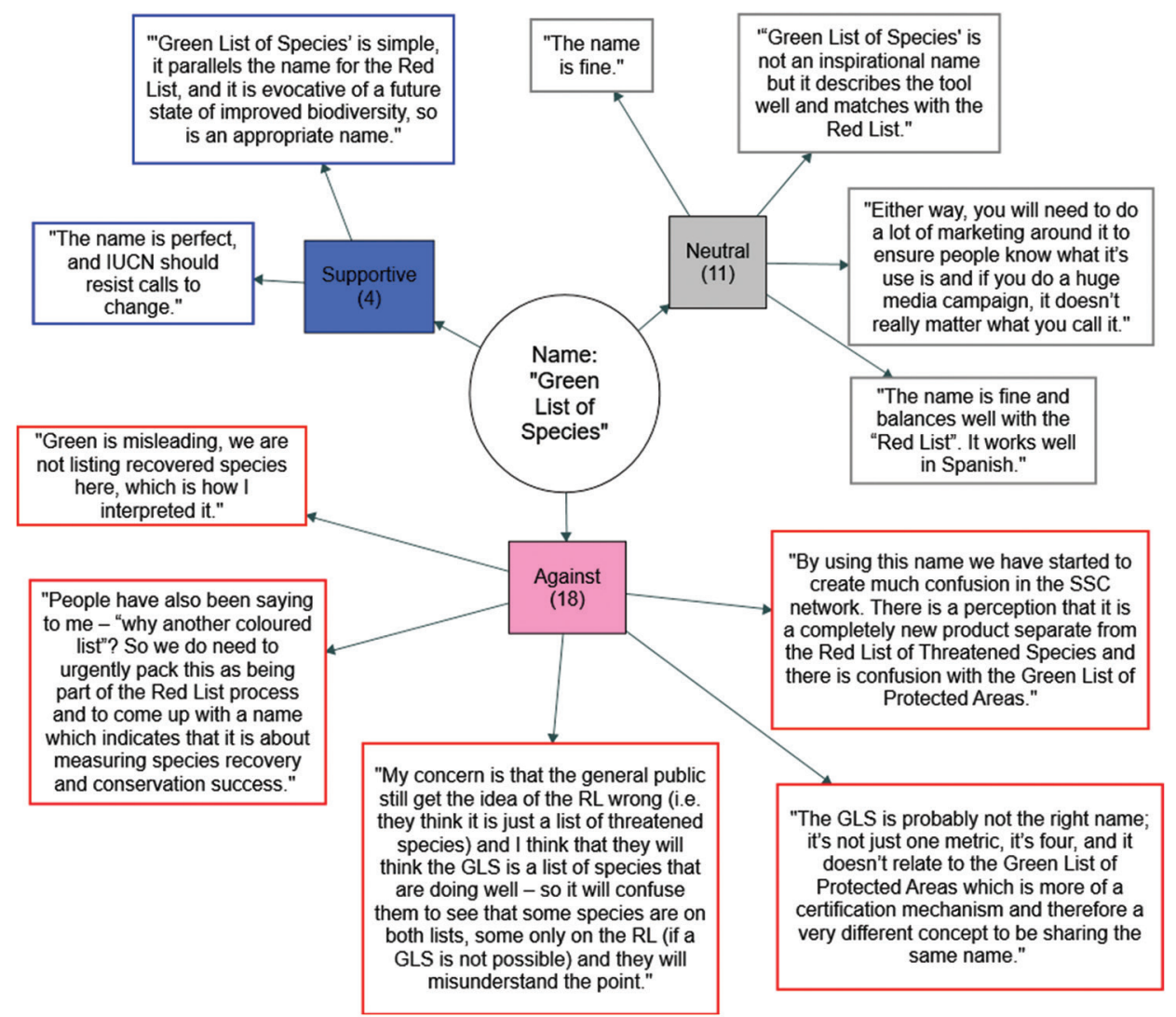

Figure 2

Examples of interview excerpts that were coded as Supportive of the name 'Green Status of Species'(GLS) (n=excerpts from 5 interviews out of 34 that discussed the name), Neutral ( $n=13)$, or Against $(n=22)$. Some participants expressed views in more than one category. Excerpts were chosen to represent the variety of views coded

we simply use number of comments to identify areas that need refinement, but a considered response to each comment received, and the changes implemented as a result, can be viewed here: https://www.iucn.org/commissions/speciessurvival-commission/resources/iucn-green-status-species/ background.

\section{Test assessor consultation}

For 139/181 test species assessments, assessors reported both time spent on assessment and whether or not any assessors had experience conducting Red List assessments. 112 of these assessments were carried out by people with Red List experience; while 27 were not. Species test assessments where assessors had Red List experience had a median of 4 spatial units $($ mean $=7.2, \min =1$, $\max =54$ ) and required a median of 4 hours to complete $($ mean $=9.9 \mathrm{hrs}, \min =0.5 \mathrm{hrs}$, $\max =96 \mathrm{hrs})$. There was a positive relationship between the number of spatial units and the amount of time required (Appendix 6). However, time required seems to increase greatly after a threshold of 15 spatial units (Appendix 6).

For test assessments where assessors did not have Red List experience, the number of spatial units chosen was distributed similarly $($ median $=4$, mean $=5.6, \min =1, \max =30)$, but assessments took longer $($ median time $=12 \mathrm{hrs}$, mean $=20.1$ hrs, $\min =2 \mathrm{hrs}, \max =80 \mathrm{hrs}$ ). There was no significant relationship between the number of spatial units and the amount of time required (Appendix 6).

\section{Integration of feedback}

Before the publication of the IUCN species recovery assessment Standard (IUCN 2021), it was updated to address the concerns raised during these key informant interviews and technical consultations. These updates to the text (and any other actions taken in response to the results of these stakeholder engagement processes) are presented in Table 2. Perhaps the most notable change was the decision to change the name of the species recovery assessment from the 'Green List of Species' to the 'Green Status of Species'.

\section{DISCUSSION}

The broad survey provided by key informant interviews from a number of end-user groups, both data generators and data users, demonstrated the usefulness of the IUCN's species recovery assessment method while highlighting concerns about userfriendliness, resourcing, and time. This mirrors conversations that took place during the development of the Red List of Threatened Species about the need to balance scientific rigour 
Table 2

Actions taken as a result of end-user consultations. This table summarises the feedback given in key informant interviews and technical consultations that resulted in implemented changes. The Results section gives a full account of the feedback, which is recounted only briefly here

\begin{tabular}{|c|c|c|}
\hline Theme & Feedback from end-users & Action(s) taken \\
\hline $\begin{array}{l}\text { Use of the name } \\
\text { "IUCN Green } \\
\text { List of Species" }\end{array}$ & $\begin{array}{l}\text { The name "IUCN Green List of Species" raises } \\
\text { communication difficulties and could be confused with } \\
\text { the IUCN Green List of Protected and Conserved Areas }\end{array}$ & $\begin{array}{l}\text { The IUCN species recovery metric is no longer known as the } \\
\text { "Green List of Species" but as the "Green Status of Species" } \\
\text { (IUCN 2021). }\end{array}$ \\
\hline Expected use & $\begin{array}{l}\text { End-users expressed a desire to use the Green Status of } \\
\text { Species to inform conservation planning }\end{array}$ & $\begin{array}{l}\text { The IUCN Species Conservation Success Task Force has } \\
\text { established a working group to investigate how Green Status } \\
\text { of Species assessments can and should be used in guiding } \\
\text { conservation planning. }\end{array}$ \\
\hline \multirow[t]{4}{*}{$\begin{array}{l}\text { Challenges- } \\
\text { complexity of } \\
\text { assessments }\end{array}$} & \multirow{4}{*}{$\begin{array}{l}\text { In the technical consultation asking for feedback on } \\
\text { the Standard and Guidelines, more than twice as } \\
\text { many comments classified as 'Clarification Needed', } \\
\text { 'Concern', 'Disagreement', or 'Misunderstanding' } \\
\text { were observed in response to the steps Assessing } \\
\text { State in Spatial Units, and Estimating Green Score } \\
\text { under Scenarios, rather than in response to the } \\
\text { steps Determining Range and Delineating Spatial } \\
\text { Units (Figure 1). }\end{array}$} & $\begin{array}{l}\text { To reduce the complexity of the step Assessing State in Spatial } \\
\text { Units, we have created an online tool to facilitate the selection } \\
\text { of state in a spatial unit (https://oxford.onlinesurveys.ac.uk/ } \\
\text { species-recovery-status-calculator); the tool guides users through } \\
\text { a series of questions, rather than requiring that the user have a } \\
\text { working knowledge of the complex regional guidelines. }\end{array}$ \\
\hline & & $\begin{array}{l}\text { To reduce the complexity of the step Assessing State in Spatial } \\
\text { Units, we recommend that a maximum number of spatial units of } \\
\text { around } 15 \text { per species will reduce the effort required }\end{array}$ \\
\hline & & $\begin{array}{l}\text { To reduce the complexity of the step Estimating Green Score under } \\
\text { Scenarios, we formed a Scenarios Working Group, which has } \\
\text { added standardised, step-by-step guidelines for evaluating scenarios } \\
\text { to the Green Status of Species Background and Guidelines (IUCN } \\
\text { Species Conservation Success Task Force 2020). }\end{array}$ \\
\hline & & $\begin{array}{l}\text { To reduce the complexity of the step Estimating Green Score under } \\
\text { Scenarios, this part of the assessment is now optional; the Standard } \\
\text { (IUCN 2021) and Guidelines (IUCN Species Conservation Success } \\
\text { Task Force 2020) now state that evaluation of the current status } \\
\text { of the species (Phase 1, Figure 1) is the minimum requirement for } \\
\text { publishing an assessment. }\end{array}$ \\
\hline \multirow{2}{*}{$\begin{array}{l}\text { Perceived } \\
\text { interaction with } \\
\text { Red List }\end{array}$} & \multirow[t]{2}{*}{ Competition for funding, time, and staff } & $\begin{array}{l}\text { The changes described above reduce the amount of time required } \\
\text { to undertake a Green Status of Species assessment. }\end{array}$ \\
\hline & & $\begin{array}{l}\text { In 2020, IUCN Council recognised the Green Status of Species as } \\
\text { part of the Red List, and it was included in the Red List Strategic } \\
\text { Plan. }\end{array}$ \\
\hline
\end{tabular}

with simplicity, generality, and ease of use (Mace et al. 2008). The more technical commentary provided by stakeholders who either read all documentation carefully for consultation purposes, or actually applied the method to a species to carry out a test case, indicated specific, challenging parts of the method that were refined to reduce overall assessment complexity, helping address key informant concerns (Table 2). Nonetheless, the majority of participants in both the key informant interviews and the technical consultation indicated support for the method.

\section{Effectively communicating about species recovery}

A key consideration in maximising uptake of a new method is effective communication. The IUCN species recovery assessment is intended to be a standardised examination of species progress toward recovery, with which any species can be evaluated-even currently threatened species (Akçakaya et al. 2018). The end-users who participated in key informant interviews suggested that the name 'Green List of Species' does not align well with this key message, and could in fact be counterproductive. The enacted change to the name 'Green Status of Species' (Table 2, reflected in IUCN 2021) not only overcomes the communication pitfalls which emerge from use of the word "list" to describe a method which can be applied to any species, but reflects the recommendation that the method be integrated within the Red List of Threatened Species as two complementary parts of species' conservation status, rather than competing lists.

\section{Utility of species recovery assessments}

Key informants identified a variety of potential uses for the data generated by the proposed IUCN species recovery assessments. Having a standard definition of species recovery (Figure 1) is not only a step forward academically, but endusers indicated it could be used in decision-making processes. Standardisation of what 'recovery' means would also facilitate monitoring efforts, not only within an organisation, but would support consistent international reporting on species recovery progress. The ability to report on recovery progress, and the impact of conservation on recovery, will serve an additional purpose: countering the negativity that often permeates messages about biodiversity conservation (Swaisgood and Sheppard 2010).

Unprompted, many participants indicated that they would foresee or desire the use of these recovery assessments in species conservation planning. While the Green Status of 
Species was designed to incentivise conservation action, it was expected to achieve this simply by providing a previously absent target for recovery and by showcasing past positive conservation impact and future potential (Akçakaya et al. 2018). Nonetheless, the desire to use novel range-wide information about species' conservation status, and areas for potential gains, in conservation planning is understandable. When discussing the applications of the assessment outputs for planning, participants suggested that the assessments could drive practical action on the conservation and restoration of key species, as well as identify areas that need increased research effort; help coordinate recovery efforts between different stakeholders; and identify overlapping conservation interventions between species to aid cost-effective scalability.

Use of the Red List of Threatened Species for purposes beyond which it was designed, e.g., conservation planning and decision-making, has been criticised and debated in the literature (e.g., Possingham et al. 2002). Nonetheless, the desire to use its data to inform planning and decision-making has proved intractable, requiring scientists to provide guidance on how the data can be appropriately used (e.g., Hoffmann et al. 2008). Based on the end-user feedback documented in this study, it appears that a similar conversation will emerge around the Green Status of Species; knowing this provides an opportunity to highlight appropriate and inappropriate uses of the data early on. While Green Status assessments, with their generation of conservation impact metrics, would provide a novel source of information that can inform planning, this information must be balanced by feasibility, cost, and stakeholder needs.

\section{Addressing end-user concerns}

Taking steps to address the concerns of potential end-users (Table 2) makes it more likely that the Green Status of Species will be used in these myriad ways. The primary concerns raised by key informant interviews were interlinked: the limited resources available to perform conservation assessments of all kinds, and the perceived complexity of the species recovery assessments (Appendix 5). While Green Status assessments were seen by the majority of interview participants to be complementary to the Red List of Threatened Species, there was nonetheless a concern that the two could end up competing for finite resources of funding, time, and staff. However, our interviews also highlighted a potential solution: the majority of participants believed that Green Status assessments should be integrated with the Red List (Appendix 4). Since these interviews took place, IUCN Council has approved the recognition of the Green Status as part of the Red List (https:/www.iucnredlist.org/about/green-status-species). As one participant describes, such integration is expected to reduce the workload of the members of the IUCN Species Survival Commission (SSC), who carry out the majority of Red List assessments:
"Having it [the Green Status of Species] completely separate [from the Red List] will create much confusion... To me it is essential that the approaches are integrated seamlessly to reduce the amount of additional work as much as possible and so that they can be perceived as being "two sides of the same coin."

Green Status assessments require much of the same information as Red List assessments - in fact, the assessment cannot be carried out unless a Red List assessment has already been completed or is being carried out concurrently (IUCN 2021). By considering the Green Status of Species a new component of the Red Listing process, rather than a separate, competing metric, then its novelty could be used as a way to stimulate interest and funding for Red List assessments.

Additionally, if the complexity of the Green Status assessment is reduced, this will also reduce the amount of resources required per assessment (noting the inherent tradeoff between precision/ realism and generality/simplicity; Levins 1966; Keith et al. 2015). One of the most technically difficult steps of the assessment identified by participants in the technical consultation was Assess State in Spatial Units (Figure 1). In this step, the Regional Red List Guidelines must be applied to each spatial unit (IUCN 2012b; Akçakaya et al. 2018). The idea that this may be a limiting factor in assessment capacity is reflected in the result that assessors with experience using the Red List spent less time on assessments than assessors without (Appendix 6). Based on our results, we recommend that the number of spatial units be capped at 15 per species in order to further reduce the effort required for this step (Appendix 6); in any case, less than $10 \%$ of test assessments exceeded 15 spatial units (Grace et al. 2021a).

The step Estimating Green Score under Scenarios was equally challenging, as measured by number of comments. While scenarios thinking is gaining traction in species conservation science (e.g., Butchart et al. 2006; Hoffmann et al. 2010, 2015; Szabo et al. 2012; Young et al. 2014; Bolam et al. 2020; Grace et al. 2021b), many conservation scientists and practitioners are unfamiliar with it, which can increase perceived or actual difficulty. By allowing assessors the option to skip the scenarios step (Table 2), the barrier to participation becomes lower, while still allowing estimation of conservation impact by organisations which value that information. Importantly, making scenarios optional would not prevent the development of a multi-species index, which would track changes in a group's recovery status over time.

\section{End-users not surveyed}

It is important to note that our key informant interviews did not canvass all categories of end-user. One bias in our dataset is that there are few interviews with organisations and individuals based in the Global South. Our results should be interpreted in the knowledge that with wider sampling, new opportunities and challenges would almost certainly be identified. As the Green Status of Species develops further (e.g., as guidelines for assessments at the national level are created), the perspectives 
of organisations and governments in the Global South will be essential.

\section{CONCLUSION}

The research-implementation gap (Knight et al. 2008) in conservation biology is well-known (Soulé 1985; Shanley and López 2009; Gossa et al. 2015). No matter how robustly researched a biodiversity conservation framework is, it is little more than an academic exercise if it is not taken up and used by stakeholders. By engaging potential end-users of the new IUCN species recovery assessment, we identified barriers to uptake - most notably, the potential issues with calling the species recovery assessment the "Green List of Species" - and implemented solutions remove those barriers - e.g., changing the name to the "Green Status of Species". Publication of the scientific methods of the assessment framework in order to stimulate feedback and critique within the scientific community (e.g., Sanderson et al. 2019; Stephenson et al. 2019) was a key step that prompted critical evaluation and strengthening of the method. The parallel process of end-user engagement described here makes it much more likely that the Green Status of Species will be used in conservation communication, monitoring, and decision-making - helping achieve the ultimate goal of moving the needle towards recovery for biodiversity.

\section{AUTHOR CONTRIBUTIONS STATEMENT}

All authors worked together to conceive and design the study; ND and HT collected the data; MG analysed the data and led the drafting of the manuscript. All authors contributed critical, intellectual content to the drafts and gave final approval of the version to be published.

\section{ACKNOWLEDGEMENTS}

We express sincere thanks to all participants of key informant interviews and technical consultations who shared their time and thoughts to make this research possible. M.G. was supported by a NERC Knowledge Exchange Fellowship as well as funding from the IUCN SSC and the World Wildlife Fund. The data collection for the key informant interviews was funded by Prince Albert II of Monaco Foundation (administered via the Cambridge Conservation Initiative Collaborative Fund).

\section{DECLARATION OF COMPETING/CONFLICTING INTERESTS}

MG, BL, EB, and EM are members of the IUCN SSC/RLC Task Force that oversaw the scientific development of the IUCN Green Status of Species.

\section{FINANCIAL DISCLOSURES}

NERC Knowledge Exchange Fellowship NE/S006125/1 awarded to $\mathrm{MG}$; Cambridge Conservation Initiative Collaborative Fund CCI-05-19-008 supported ND and HT.

\section{RESEARCH ETHICS APPROVAL STATEMENT}

This manuscript analyses data collected previously for an institutional report (Dudley and Timmins 2021). The data collection was overseen by Global Wildlife Conservation, which does not have a formal Ethics Review board/process. An explanation of how the ethics of responsible data collection were addressed can be found in the methodology section of this manuscript.

\section{DATA AVAILABILITY}

Full interview texts are available in Dudley and Timmins (2021).

\section{REFERENCES}

Akçakaya, H.R., E.L. Bennett, T.M. Brooks, et al. 2018. Quantifying species recovery and conservation success to develop an IUCN Green List of Species. Conservation Biology 32(5): 1128-1138.

Bolam, F.C., L. Mair, M. Angelico, et al. 2020. How many bird and mammal extinctions has recent conservation action prevented? Conservation Letters 14(1): e12762.

Butchart, S.H., A.J. Stattersfield, and N.J. Collar. 2006. How many bird extinctions have we prevented? Oryx 40(3): 266-278.

Christoffersen, L.E. 1997. IUCN: a bridge-builder for nature conservation. Green Globe Yearbook 1997: 59-70.

Dudley, N. and H.L.Timmins. (eds.) 2021. A survey of user attitudes towards the proposed IUCN Green Status of Species. Gland, Switzerland: IUCN. DOI: https://doi.org/10.2305/IUCN.CH.2021.03.en

Fazey, I., A.C. Evely, M.S. Reed, et al. 2013. Knowledge exchange: a review and research agenda for environmental management. Environmental Conservation 40(01): 19-36.

Gossa, C., M. Fisher, and E.J. Milner-Gulland. 2015. The research-implementation gap: how practitioners and researchers from developing countries perceive the role of peer-reviewed literature in conservation science. Oryx 49(1): 80-87.

Grace, M.K., H.R. Akçakaya, E.L. Bennett, et al. 2021a. Testing a global standard for quantifying species recovery and assessing conservation impact. Conservation Biology.

Grace, M.K., J.W. Bull, C, Carrero, et al. 2021b. Building robust, practicable counterfactuals and scenarios to evaluate the impact of species conservation interventions using inferential approaches. Biological Conservation, 261: 109259.

Hockings, M., J. Hardcastle, S. Woodley, et al. 2019. The IUCN Green List of Protected and Conserved Areas: setting the standard for effective area-based conservation. Parks 25(25.2): 57-66.

Hoffmann, M., T.M. Brooks, G.A.B. Da Fonseca, et al. 2008. Conservation planning and the IUCN Red List. Endangered Species Research 6(2): $113-125$.

Hoffmann, M., C. Hilton-Taylor, A. Angulo, et al. 2010. The impact of conservation on the status of the world's vertebrates. Science 330(6010): 1503-1509

Hoffmann, M., J.W. Duckworth, K. Holmes, et al. 2015. The difference conservation makes to extinction risk of the world's ungulates. Conservation Biology 29(5): 1303-1313.

IUCN. 2012a. WCC-2012-Res-041-EN-Development of objective criteria for a Green List of species, ecosystems and protected areas. https:// portals.iucn.org/library/node/44008. Accessed on July 6, 2020.

IUCN. 2012b. Guidelines for Application of IUCN Red List Criteria at Regional and National Levels: Version 4.0. https://www.iucn.org/ 
160 / Grace, et al.

content/guidelines-application-iucn-red-list-criteria-regional-andnational-levels-version-40. Accessed on June 7, 2021.

IUCN. 2020. IUCN Members. https://www.iucn.org/about/members/iucnmembers. Accessed on July 6, 2020.

IUCN. 2021. IUCN Green Status of Species: a global standard for measuring species recovery and assessing conservation impact. Version 2.0. Gland, Switzerland: IUCN. DOI: https://doi.org/10.2305/IUCN.CH.2021.02.en

IUCN Species Conservation Success Task Force. 2020. Background and Guidelines for the IUCN Green Status of Species. Version 2.0. Prepared by the IUCN Species Conservation Success Task Force. Downloadable from https://www.iucnredlist.org/resources/green-status-assessmentmaterials. Accessed on June 7, 2021.

IUCN and World Commission on Protected Areas (WCPA) (2017). IUCN Green List of Protected and Conserved Areas: Standard, Version 1.1. Gland, Switzerland: IUCN.

Jones-Walters, L. and A. Cil. 2011. Biodiversity and stakeholder participation. Journal for Nature Conservation 19(6): 327-329.

Keith, D.A., J.P. Rodríguez, T.M. Brooks, et al. 2015. The IUCN Red List of Ecosystems: motivations, challenges, and applications. Conservation Letters 8(3): 214-226.

Knight, A.T., R.M. Cowling, M. Rouget, et al. 2008. Knowing but not doing: selecting priority conservation areas and the research-implementation gap. Conservation Biology 22(3): 610-617.

Levins, R. 1966. The strategy of model building in population biology. American Scientist 54(4): 421-431.

Mace, G.M. 2000. Summary of the results of the review of IUCN Red List categories and criteria 1996-2000. In: IUCN Red List of threatened species.(ed. Taylor, H.). Pp. 57-61. Gland, Switzerland, and Cambridge: International Union for the Conservation of Nature.

Mace, G.M. and R. Lande. 1991. Assessing extinction threats: toward a reevaluation of IUCN threatened species categories. Conservation Biology 5(2): 148-157.
Mace, G.M., N. Collar, J. Cooke, et al. 1992. The development of new criteria for listing species on the IUCN Red List. Species 19:16-22.

Mace, G.M., N.J. Collar, K.J. Gaston, et al.2008. Quantification of extinction risk: IUCN's system for classifying threatened species. Conservation Biology 22(6): 1424-1442.

Maxwell, J., S. Allen, T. Brooks, et al. 2018. Engaging end-users to inform the development of the global standard for the identification of key biodiversity areas. Environmental Science \& Policy 89: 273-282.

Possingham, H.P., S.J. Andelman, M.A. Burgman, et al. 2002. Limits to the use of threatened species lists. Trends in Ecology \& Evolution 17(11): 503-507.

Rodríguez, J.P., K.M. Rodríguez-Clark, D.A. Keith, et al. 2012. IUCN Red List of Ecosystems. Surveys and Perspectives Integrating Environment and Society 5(2): 61-70.

Shanley, P. and C. López. 2009. Out of the loop: why research rarely reaches policy makers and the public and what can be done. Biotropica 41(5): 535-544.

Soulé, M.E. 1985. What is conservation biology? BioScience 35(11): 727-734.

Sterling, E.J., E. Betley, A. Sigouin, et al. 2017. Assessing the evidence for stakeholder engagement in biodiversity conservation. Biological Conservation 209(2017): 159-171.

Swaisgood R.R. and J.K. Sheppard. 2010. The culture of conservation biologists: show me the hope! BioScience 60(8): 626-630.

Szabo, J.K., S.H.M. Butchart, H.P. Possingham, et al. 2012. Adapting global biodiversity indicators to the national scale: a Red List Index for Australian birds. Biological Conservation 148(1): 61-68.

Young, R.P., M.A. Hudson, A.M.R. Terry, et al. 2014. Accounting for conservation: using the IUCN Red List Index to evaluate the impact of a conservation organisation. Biological Conservation 180(2014): $84-96$. 